\title{
“ES TÚ HIJO, PERO NO ES TUYO" VÍNCULO, RECIPROCI- DAD Y AFECTOS EN LEONERA DE PABLO TRAPERO
}

\author{
"HE IS YOUR SON, BUT HE ISN"T YOURS" LINK, RECI- \\ PROCITY AND AFFECTION IN PABLO TRAPERO'S LEONERA
}

\section{"ELE É SEU FILHO, MAS NÃO É SEU" LIGAÇÃO, RECIPRO- CIDADE E AFECTO NA LEONERA DE PABLO TRAPERO}

\author{
Renatto Jorge Merino Solari ${ }^{1}$ \\ Universidad Nacional Mayor de San Marcos \\ rmerinosolari@gmail.com \\ ORCID: 0000-0003-4108-6595 \\ Iris Maria Neyra Rivera ${ }^{2}$ \\ Universidad Nacional Mayor de San Marcos \\ ineyra83@gmail.com \\ ORCID: 0000-0001-8806-1315
}

Recibido: $11 / 03 / 21$

Aceptado: 20/03/21

1 Licenciado y Magíster en Antropología de la Universidad Nacional Mayor de San Marcos. Realizó estudios de doctorado en Educación en la misma universidad. Se desempeña como docente de pregrado y postgrado en la Facultad de Educación de la Universidad Peruana Cayetano Heredia.

2 Psicóloga de la Universidad Nacional Mayor de San Marcos con Segunda Especialidad en Psicología Forense por la Universidad Nacional Federico Villareal y Estudios en Políticas y Programas con la Niñez y Adolescencia en la Universidad Antonio Ruiz de Montoya. Se desempeña como Especialista del Programa Nacional Aurora del Ministerio de la Mujer y Poblaciones Vulnerables. 


\section{Resumen}

El artículo analiza la película Leonera de Pablo Trapero. El filme representa la historia de Julia, una mujer joven y embarazada, que ingresa a prisión y debe luchar por ganarse un espacio entre las presas, así como defender el derecho a la crianza de su hijo. A partir de las ideas de vínculo y reciprocidad se explora la forma en que la protagonista construye sus interacciones sociales y afectivas al interior de la prisión. Concluimos que Julia configuró una compleja red de intercambios (servicios, bienes, afectos, sentimientos y corporalidades) que le permitió dar sentido a su experiencia en la cárcel.

Palabras claves: película Leonera, cárcel, vínculo, reciprocidad, afectos.

\section{Abstract}

The article analyzes the film Leonera by Pablo Trapero. The film represents the story of Julia, a young and pregnant woman, who enters prison and must fight to achieve a space among the inmates, as well as defend the right to raise her child. From the ideas of bond and reciprocity, the way in which the protagonist constructs her social and affective interactions within the prison is explored. We conclude that Julia configured a complex network of exchanges (services, goods, affections, feelings and corporalities) that allowed her to give meaning to her experience in prison.

Keywords: leonera film, jail, link, reciprocity, affections.

\section{Resumo}

O artigo analisa o filme Leonera de Pablo Trapero. O filme representa a história de Julia, uma mulher jovem grávida, que entra na prisão e deve lutar para conquistar um espaço entre as presidiárias, além de defender o direito de criar seu filho. A partir das ideias de ligação e reciprocidade, exploramos a forma como a protagonista constrói suas interações sociais e afetivas dentro da prisão. Concluímos que Julia configurou uma complexa rede de trocas (serviços, bens, afetos, sentimentos e corporalidades) que lhe permitiram dar sentido à sua experiência na prisão.

Palavras-chave: filme Leonera, prisão, ligação, reciprocidade, afetos. 


\section{Introducción}

El Nuevo Cine Argentino (NCA) tiene su emergencia en los años noventa del siglo pasado y durante las primeras décadas del siglo XX su mayor difusión e influencia en Latinoamérica. Se trata, en gran medida, de un cine de autor, de carácter independiente que propone una mirada diferente de la sociedad en Argentina. Las producciones del NCA "no apuestan a un protagonista moralmente correcto, sino a un encuadre de un problema institucional, social, politico, etc., donde todos los que participan son parte de él, pero también pueden ser la solución” (Di Leo Razuk, 2017, p. 68).

Campero divide a las producciones del NCA, atendiendo a su relación con la realidad, en "un cine realista y otro no realista" (2009, p. 26). El cine realista, en el cual ubica a Trapero, presenta las siguientes características:

En las películas realistas hay un borramiento entre lo documental y lo ficcional, una mayor sensación de cercanía que otras películas no pertenecientes al nuevo cine. Muchas veces no se sabe qué es guionado y qué surgió durante el rodaje; y suele recurrirse a no actores, que responden a tipos físicos más que a estereotipos sociales. El cine realista recuperó para el cine argentino la facultad del uso del lenguaje hablado muy concreto y verdadero, en el marco de un tratamiento sofisticado de las distintas capas de sonido, en la que todo lo que se escucha forma parte deliberada de la puesta en escena. En cuanto a las temáticas, su vinculación con la realidad no se afirma con el tratamiento de noticias urgentes (recurso tan común durante la primera mitad de la década de 1990) sino con el anclaje a partir de referentes fácilmente identificables de la vida cotidiana y del momento histórico, sin la necesidad ni la convocatoria a realizar lecturas alegóricas. (Campero, 2009, pp. 26)

Pablo Trapero es uno de los directores más importantes de este grupo. Su película Mundo Grúa (1999), ganadora de los premios al Mejor Director y Mejor Actor en el Buenos Aires Fes- 
tival Internacional de Cine Independiente (BAFICI), se considera uno de los momentos iniciales del NCA. Entre sus largometrajes podemos destacar filmes como El bonaerense (2002), Leonera (2008), Carancho (2010), Elefante blanco (2012), El clan (2015) -ganadora del premio Goya a la mejor película iberoamericanay La quietud (2018).

Las producciones de Trapero evidencian las contradicciones del proyecto modernizador en la Argentina contemporánea representando con agudeza la profunda crisis por la que atraviesan sus principales instituciones. Así, "retrata cómo el Estado, las cárceles, el hospital público y la policía (...) están en ruinas y cómo sus propios miembros se convierten en víctimas porque estas ruinas los arrinconan en situaciones problemáticas, aporéticas o en callejones sin salida" (Di Leo Razuk, 2017, p. 69). El entramado institucional reflejado en los filmes de Trapero genera imaginarios particulares que no son los "cuerpos dóciles" con "subjetividades modeladas", propios de la normalización institucional moderna. Por el contrario, Trapero nos muestra personajes que reproducen "fragmentos inconexos de retóricas institucionales que giran en el vacío. Estas hilachas discursivas establecen un contrapunto con sus prácticas. Y los diversos recorridos subjetivos están atravesados por esta imposibilidad" (Mizrahi, 2017, p. 134).

Sus personajes actúan en mundos difusos, en lugares donde los límites entre lo formal e informal se tornan porosos; en este sentido, son transgresores que desbordan las normas y los límites de lo institucional. Sin embargo, no se trata de la figura del individuo rebelde y antisistema, sino de personas que, en gran medida, se encuentran configuradas por lógicas institucionales burocráticas, ineficientes y corruptas; son personajes que interactúan en espacios en los que la norma y el orden se negocian en relación y al margen del discurso oficial. Y, es a partir de estos escenarios, casi anómicos, que (re) definen su agencia personal. Por tanto, estamos ante individuos contradictorios, atravesados por dilemas y pasivos existenciales que 
vivencian situaciones límites. De esta forma, Trapero logra elaborar "historias que muestran situaciones conflictivas en las que se entrecruzan agentes sociales con caracteristicas completamente diferentes" (Bonacci et al. 2014, p. 170).

Leonera es su quinto largometraje, obtuvo el Premio Ariel a la mejor película Iberoamericana y el Premio Sur a la mejor actriz revelación (Martina Gusman). En el XII Festival de Cine de Lima (2008) fue galardonada con premios a la mejor película, mejor guion, mejor fotografía y a la mejor actriz. Leonera narra una historia acerca de ser mujer y de la maternidad en prisión. Fue filmada en escenarios reales con personajes que formaban parte del mundo penitenciario. Al respecto, en una entrevista Trapero declara:

No sólo hay ex presidiarios; hay presidiarios reales, así como celadores y celadoras que trabajan ahí en serio y familiares de presos. Todo está filmado en cárceles reales de Olmos en Hornos. Toda la película, en suma, está atravesada por ese limite entre lo real y lo ficticio (2008, p. 7).

La película, intersección entre la ficción y el documental, será abordada a partir de dos ideas ejes: reciprocidad y vínculo. La primera, reciprocidad, la entendemos como una pauta social que se manifiesta en intercambios de bienes, servicios, dones y afectos que se generan entre los miembros de un grupo o comunidad e influyen tanto en sus decisiones como en sus acciones. Las relaciones de reciprocidad configuran un sistema de intercambios vinculantes que ligan a las personas y al grupo hacia adentro pero también hacia afuera, en las relaciones con los otros (Malinowski, 1978). En contexto, la reciprocidad puede funcionar de forma simétrica, es decir, a partir de intercambios igualitarios; y de forma asimétrica, basada en relaciones de poder y desigualdad (Mayer, 2004).

En cuanto a la idea de vínculo, la entendemos como la relación que establecen dos personas retroalimentándose mutuamente y generando alianzas para beneficio de ambas partes. El 
vínculo funciona como un puente que permite el intercambio, la interacción, así como el flujo de afectos y emociones. Como han demostrado los estudios sobre infancia institucionalizada, la variable vínculo afectivo es fundamental para el desarrollo emocional y conductual de la persona (Ramírez, 2007). Desde nuestra mirada, el énfasis estará en el carácter saludable del vínculo, en las interacciones que fortalecen y enriquecen a las personas. En el intercambio, en el compartir situaciones, se generan las posibilidades para mejorar nuestra existencia. En otras palabras, la experiencia de una de las partes sirve de insumo para la mejoría de la otra y viceversa. Es característico de la condición humana construir vínculos permanentemente; los sujetos necesitan de la interacción con el otro todo el tiempo. Cuando la convivencia social se convierte en una relación asimétrica, de inequidad, es decir, una relación de poder, el vínculo termina disolviéndose.

A partir de este ideario exploraremos las interacciones que Julia construye desde el espacio penitenciario con Marta, su compañera de prisión, Tomás, su hijo, y Sofía, la madre. Son las personas con quienes Julia establece conexiones significativas desde el violento y deprimido mundo cotidiano en el cual se encuentra. En este escenario logró conformar una red de reciprocidades y vínculos interpersonales, así como una compleja urdimbre emocional/sentimental/corporal que le permitió dar sentido a su experiencia en la cárcel.

\section{Vinculo, reciprocidad y afectos en Leonera}

El filme gira en torno al personaje de Julia Zárate (Martina Gusman), una joven de la clase media de Buenos Aires. Un día despierta en su departamento ensangrentada y con evidencias de haber sido golpeada; sin embargo, parece no ser consciente de ello. Durante el día y, a partir del descubrimiento de las huellas de violencia en su cuerpo, intenta recordar lo sucedido. Al retornar a su departamento encuentra una escena macabra: 
los cuerpos de las personas con las que convivía, Nahuel Heredia, su pareja, y Ramiro Nievas (Rodrigo Santoro), amigo de Nahuel, yacen en el piso con evidencias de haber sufrido violencia severa. Nahuel está muerto, Ramiro agoniza, pero sobrevivirá e irá a prisión. Julia, mientras tanto, desesperada y sin comprender bien lo sucedido, conversa por teléfono: "no sé qué pasó", es lo que repite entre lágrimas a su interlocutora. Es detenida y le dictan prisión preventiva. En prisión ingresa al pabellón de madres, pues está gestando. En un primer momento muestra rechazo al embarazo, pero progresivamente irá cambiando esta actitud y la maternidad será uno de los vínculos más intensos que experimente en la cárcel. En este lugar conoce a Marta Rojo (Laura García), mujer indígena con quien establece una de sus relaciones significativas. Marta la guía y orienta apoyándola en el cuidado de su hijo, Tomás (Tomás Plotinsky). Cuando Sofía (Elli Medeiros), su madre, aparece en el filme para visitarla se inicia una disputa por el niño: ¿cuál es el lugar más conveniente para que viva Tomás: la cárcel o el acomodado departamento de la abuela? Julia es condenada a 10 años de prisión. Finalmente, atrapada entre el engaño de su madre y el abogado y por un sistema judicial que no responde a sus necesidades de madre decide fugar y recuperar a su hijo.

La mayor parte de los hechos transcurren en el recinto carcelario, cuya configuración resulta ambivalente. Por una parte, es una cárcel en el sentido estricto, en la medida que en ella se encuentran mujeres que están privadas de su libertad; por otra parte, y para el común denominador, parece no serlo, pues sus ocupantes cuentan con beneficios que el resto de la población no tiene, como el tránsito libre en el pabellón, espacios lúdicos para los niños, la posibilidad de llevar a los hijos de las presas a un lugar en el que los cuidan y otras cosas más que responden a ciertas necesidades de estas mujeres y que las acerca a la figura imaginada de la madre con sus hijos. Es un lugar de tránsito, una leonera, para las mujeres detenidas y que Marta 
lo sintetiza así: "agradecé que tienes la panza, este pabellón no es la cárcel".

Julia es una interna diferente, su condición de clase social, su aspecto físico (al ingresar al presidio una interna la llama "rubia idiota") marcan una alteridad con respecto a la mayoría de las internas, de sectores populares y marginales. En el pabellón conoce a Marta, interna de origen indígena y madre de dos hijos, encerrada, como dice ella: "por pobre, por pelotuda, por eso". Se genera entre ambas una relación cercana e interdependiente que oscila entre la relación de amistad y la de pareja. La relación se inició en las duchas. En medio de una gresca entre dos reclusas, originada por la forma en que una de ellas tomó al hijo de la otra, Marta abraza a la temerosa Julia, que previamente había sido manoseada por una de las mujeres contendientes y salen juntas del baño. De esta forma, Marta asume el rol de protectora y representante presentándola al grupo de presas:

Así Marta, quien ya tiene una posición pública en ese espacio periférico aunque insertado en la ciudad, cumple esa función y la introduce también a ella en lo social, es decir, en el espacio de la cárcel. Julia así pasa a ser "de acá". (Luengo, 2017, p.50)

Julia pasa a ser "de acá" convirtiéndose en parte del nosotras, pero mediada por Marta quien asume el rol de intermediaria. Julia acepta esta situación con resignación, como algo inevitable, pero a la vez es su estrategia para sobrevivir en medio de un ambiente que le resulta extraño y hostil.

La incorporación al nuevo escenario implica también cambios en su cuerpo: "ella misma va cambiando su aspecto físico, de ser rubia, acaba siendo también morocha, vistiendo ropa de deporte, mostrando la panza" (Luengo, 2017, p. 51). La evolución corporal de Julia expresa la inmersión en el mundo carcelario. Su cuerpo va transitando de la figura estilizada de una mujer joven, recién embarazada, al cuerpo materno del embarazo 
avanzado y, finalmente, a la mujer totalmente incorporada a la prisión que simbólicamente se expresa en el corte de cabello y en el tatuaje marcado en su espalda.

Marta no solo la cuida de la agresividad de las otras internas, también la atiende como lo haría una madre/amiga/pareja. Por su parte, Julia le consigue tarjetas para comunicarse por teléfono, objeto muy apreciado por las presas y que Julia puede conseguir con relativa facilidad gracias a los recursos familiares. Es el punto de partida de una dinámica de reciprocidades que también se manifestará en el nivel de los afectos, con los niños, y en los intercambios amorosos. Las caricias y besos de Marta, que inicialmente fueron rechazadas por Julia, terminan siendo aceptadas. De este modo, logran integrar sus familias para constituir una familia mayor compartiendo celda, afectos y la crianza de sus hijos. Así, al nacer el hijo de Julia lo crian juntas. Marta le enseña las primeras atenciones y cuidados de la maternidad, incluso le da de lactar al pequeño Tomás.

A pesar de pertenecer a mundos distintos logran complementarse para beneficio de ambas. Marta está presa, como ya hemos mencionado, por pobre, lo cual podemos entenderlo como una falta de recursos para volver operativa una estrategia legal que le permita mejores condiciones. En cambio, Julia puede movilizar sus recursos familiares para lograr lo que su compañera no puede alcanzar. Por ello Marta le dice: "tú tienes plata, si tienes plata se va a hacer todo más fácil”. Pero la mujer indigena tiene las habilidades sociales necesarias para sobrevivir en prisión, así como fuera de ella, en los límites de la legalidad. Cuando Julia logra huir con su hijo es Marta quien, a través de sus contactos, le facilita documentación falsa para que puedan cruzar la frontera. Continúa acompañando a Julia aun después de haber salido de prisión y es quien la guía hacia la "libertad". En medio de ello, el intercambio de afectos es manifiesto a través de gestos, miradas y caricias.

Una red de reciprocidades materiales y afectivas permite a las dos mujeres obtener, por caminos diferentes, sus objetivos. 
Es una relación de amistad, de favores y afectos que evidencian el vínculo generado. Ambas esperan que la otra persona esté bien y actúan dando y recibiendo guiadas por sus sentimientos y emociones. No obstante, cada una sabe cuál es su límite. En ningún momento una le dice a la otra: quiero continuar contigo cuando salga de acá. Las dos son conscientes de que no van a estar juntas, entonces no hay reclamos ni reproches. No es una cuestión posesiva ni egoísta. Afuera de prisión cada una continúa con su ritmo familiar/social; Marta con su familia trabajando para sostener a sus hijos y Julia en tránsito hacia otro país buscando la "libertad". En este caso, los barrotes no solo separan las celdas, también funcionan como barreras sociales demarcando el territorio y las interacciones de cada una.

Por otra parte, evidencian ser personalidades resilientes. Es interesante destacar cómo en un escenario deprimido, autoritario y violento son capaces de generar conexiones, intercambios positivos y configurar una sinergia que les permitió sobrellevar la experiencia carcelaria de la mejor manera posible, sin engancharse en la circularidad que suelen propiciar las situaciones dolorosas. Por el contrario, aprovechan al máximo los intersticios que permite el sistema para reconstruir sus vidas.

En cuanto a la maternidad, Julia se entera de su embarazo al ingresar a prisión. En este contexto debemos comprender el rechazo inicial a su condición de gestante. Está vivenciando con gran intensidad una mezcla de emociones: incertidumbre, rechazo, confusión, cólera, impotencia y miedo. Ser involucrada en un crimen sin poder recordar con claridad cómo sucedieron los hechos, la detención preventiva, un juicio en el cual aparece como la principal responsable, la desconfianza en su abogado, un espacio extraño y violento que resulta totalmente diferente a su contexto cotidiano; en suma, un conjunto de situaciones difíciles de procesar para una persona que, como muestra la escena inicial, de repente despierta y, sin ser consciente de los hechos, su vida habia cambiado radicalmente. En medio de este momento traumático es una reacción plausible intentar evitar 
el embarazo. Si una persona experimenta una serie de eventos traumáticos y su futuro se torna incierto, son esperables reacciones de este tipo y, probablemente, otras conductas que nieguen o dañen su persona. Los espacios limitados que restringen las libertades suelen generar sufrimiento, dolor y depresión; son frecuentes los daños, las autolesiones y diversas formas de violencia contra sí mismo y contra los otros.

El vínculo entre Julia y Tomás se va construyendo en la convivencia, en el compartir madre-hijo como parte de las interacciones con el personal penitenciario, las demás detenidas y, especialmente, con Marta. La relación con Tomás reorienta en Julia la noción de temporalidad y modifica sus prioridades. El tiempo que permanece presa es redefinido en función de la posibilidad de estar junto a su hijo. La preocupación acerca de su culpabilidad se recontextualiza y se vuelve fundamental para ella demostrar su inocencia en la medida que de ello depende la relación con Tomás. El tiempo de la prisión ya no es el de la ley, sino el del vínculo madre-hijo y la necesidad de seguir juntos. La vida de Julia ha cambiado. En este sentido, se reafirma la idea de que los vínculos no están biológicamente establecidos; por el contrario, son construidos en relación con el tipo de experiencias, contextos, tiempos y espacios que comparten las personas.

En general, la relación de las madres presas con sus hijos es central. Los hijos definen los escenarios que van a vivenciar sus madres, como en el caso de los privilegios y las concesiones que ostentan. Pero a la vez, son secundarios, como en las situaciones de violencia autoinfligida o en el motín. Los niños influyen en la forma cómo reaccionan ellas. Lo que le sucede a un niño afecta el control de las emociones maternas que pueden transitar de la pasividad a la agresividad más feroz dependiendo de las circunstancias. Durante la presentación de Leonera en el Festival de Cine de Lima, Martina Gusman describió cómo Julia termina convirtiéndose en una mezcla de leona y mono para poder sobrevivir en prisión, y esto incluye la cercanía a 
su hijo. En síntesis, la relación con sus hijos es el vínculo más sólido que logran construir y la base de la fuerza emocional que las sostiene.

La crianza de un niño en la cárcel no es lo esperado por una madre ni por su familia. En este sentido, la escena del niño balanceándose sujeto a los barrotes está cargada de simbolismo. Por una parte, nos está diciendo que se trata de un niño encerrado, que él también, a su modo, es un prisionero y ello, probablemente, dejará huellas imborrables en su ser. Por otra parte, muestra cómo estas rejas, expresión de la violencia penitenciaria, se convierten en parte del juego. El niño normaliza su situación y también puede estar bien. La inmersión de Tomás en el paisaje carcelario acompaña a la de su madre. En consecuencia: ¿qué es lo mejor para el niño: continuar junto a su madre o ser acogido por algún familiar cercano? Más allá de lo que establezca la norma jurídica, las posiciones pueden ser opuestas e igualmente válidas.

Sofía, la madre de Julia, es una mujer acomodada que vive en el extranjero y retorna al país por la situación de su hija. Su entrada en escena no tiene antecedentes y sorprende a Julia, así como al espectador. En un primer momento es rechazada por su hija, sin embargo, mantiene el empeño en visitarla y estar cerca de ella para ayudarla. Gracias a sus posibilidades económicas le contrata un abogado para su defensa. Poco a poco parece recuperar la confianza de Julia.

La actitud de Sofía es difícil de contextualizar, pues se trata de un personaje que aparece y desaparece al ritmo de lo que dura una visita. Lo que se explicita es la idea de una relación conflictiva entre ambas. Es admisible suponer que la explicación se encuentra en experiencias pasadas. En ese marco, la conducta de Sofía es la de una persona que busca redimirse, que desea reparar al otro por un daño, una falta, una ausencia; por algo que en su momento debió haber hecho, pero no hizo. El argumento de la abogada Elsa (Clara Sajnovetzky) durante el juicio oral brinda pistas en este sentido: "De chica, una ma- 
dre la abandona y la deja al cuidado de su padre enfermo (...) los abusos que sufrió Julia no son delitos, pero sirvieron para desestabilizarla, denigrarla, humillarla hasta los límites de lo tolerable (...)". La mamá no estuvo allí cuando correspondía, probablemente en circunstancias más llevaderas tampoco estuvo presente. Ahora que mi hija está presa, involucrada en un hecho escabroso, no puedo abandonarla nuevamente. Esta parece ser la idea que abruma a Sofía. Estar presente es casi un mandato imperativo para ella. Por tanto, lo que prima es una carencia, el sentimiento de culpa por no haber cumplido con su hija: Sofía está buscando "curarse", empero en su intento por "hacer el bien" causa daño.

Cuando nace Tomás, la abuela quiere tenerlo. Le preocupa las condiciones psicosociales a las que está expuesta la criatura y durante una salida, para llevarlo a una consulta médica, aprovecha la situación para quedarse con él. Después de unos días retorna a la cárcel junto al abogado, pero no retorna a Tomás. La escena que sigue es una de las mejores y más intensas. Julia le pregunta por su hijo y le pide que lo traiga, ante la negativa de Sofía, una angustiada Julia insiste: "mamá traémelo a Tomás, te lo pido bien por favor, andá a buscarlo...”. Pero Sofía no está dispuesta a aceptar y desconoce el beneficio que le asiste a Julia de cuidar a su hijo: "es tú hijo, pero no es tuyo". La situación de prisionera despoja a Julia de sus derechos, la vuelve vulnerable al engaño y al abuso de poder. La joven madre replica desesperada: "es mío, es mi hijo y es mío, así que andá y traémelo". La negativa de Sofía descontrola a Julia. La indignación y la rabia son inmensas e insulta y amenaza con ferocidad a su madre: "hija de puta te voy a matar, no te voy a lastimar, te voy a matar". La leona mezclada con mono había entrado en acción para mostrar la fuerza del vínculo madre-hijo. Finalmente, Julia es controlada con mucho esfuerzo por el personal carcelario y confinada a una celda de castigo en donde se autolesiona. En este punto se produce un giro en la película. La pérdida de su hijo dispara el proceso de redefinición identitaria 
que venía ocurriendo con Julia. Ella, que habia tenido una actitud pasiva, sumisa y temerosa se convierte en la incitadora de un motín en el penal. Atrapada entre el engaño de su familia y un sistema judicial que la condena a diez años de prisión por homicidio simple decide huir de prisión para recuperar a su hijo y reiniciar una vida familiar en un nuevo territorio. Algo que conseguirá por medios ilegales.

\section{Conclusión}

A partir de las ideas de reciprocidad y vínculo nos propusimos explorar las interacciones que Julia construye desde el espacio penitenciario con Marta, Tomás y Sofía. Se trata de relaciones particulares, contradictorias y complementarias. Marta es la compañera más importante que tiene en el pabellón. Inicialmente es quien la conduce y le permite ganarse un lugar en el mundo penitenciario. Es el principal medio que tiene Julia para integrarse al grupo de presas. Junto a sus hijos conforman una familia al interior del penal y actúan apoyándose mutuamente. Entre Julia y Marta no hay una situación de poder en la cual lo mío prima sobre lo tuyo o lo que yo vivencio es más importante que tú sentir; por el contrario, la interacción es el puente que les permite alimentarse una junto a la otra. Es importante resaltar que, en un primer momento, la relación fue de tutelaje por parte de Marta y que progresivamente evolucionó hacia formas de interacción más simétricas. Se evidencia que los vínculos no se generan en una etapa determinada de la vida; antes bien, pueden surgir y desarrollarse en cualquier momento, en base a vivencias y expectativas compartidas.

Con Tomas generó el vínculo más importante, es la relación afectiva más fuerte e intensa que edifica en la cárcel. Son interdependientes y la estabilidad emocional de ambos depende de la cercanía y del tipo de convivencia que pudieran establecer. Además, el binomio madre-hijo deviene en el fundamento del proceso de redefinición identitaria que Julia experimenta 
en prisión: de una joven desorientada, deprimida, asustada y sin mayores fines; se convirtió en una mujer con un proyecto de vida definido.

Mientras Marta y Tomás son parte del nosotros, Sofía representa la otredad. La madre es la alteridad que encarna lo extraño, la desconfianza, el peligro. Desde estas coordenadas establecieron una relación conflictiva en la que los intercambios se negocian en función a intereses particulares sin generar arraigo. Se trata de una coexistencia pacífica, siempre provisional y de carácter latente que las distancia emocionalmente.

En medio de esta dinámica, en la que se mezclan razón instrumental y emociones, Julia configuró una compleja red de intercambios (servicios, bienes, afectos, sentimientos y corporalidades) que le permitió dar sentido a su experiencia en la cárcel.

\section{Referencias bibliográficas}

Bonacci, S., Pécora, C. y Ronco, J. (2014). Pablo Trapero: la calle en el cine. Revista TOMA UNO (N. 3), pp. 169-180. Facultad de Artes, Universidad Nacional de Córdova, Argentina. Recuperado de: https://revistas.unc.edu.ar/index.php/toma1/ article/view/9300

Campero, N. (2009). El nuevo cine argentino: Raíces y evolución. Revista de cine Ventana Indiscreta, N. 2, Segundo semestre del 2009, Lima, pp. 23-28.

Di Leo Razuk, A. (2017). Reflexiones teológico-políticas en Elefante Blanco. En Callegaro, A., Di Leo Razuk, A. y Mizrahi, E. (Compiladores). Cine y cambio social: imágenes sociopoliticas de la Argentina 2002-2012. San Justo: Universidad Nacional de La Matanza, 67-90. Recuperado de: http://biblioteca.clacso.edu.ar/clacso/se/20170630011806/Cine_y_cambio_social.pdf

Luengo, A. (2017). Buenos Aires como prisión - Paraguay como utopia: Formas de resistencia y la creación de espacios alternativos en Leonera (2008) y El Niño Pez (2009). Revista Iberoamericana. Vol LXXXIII, Num. 258, enero-Marzo 2017, 
41-55. University Library System, University of Pittsburgh. Recuperado de: http://revista-iberoamericana.pitt.edu/ojs/ index.php/Iberoamericana/article/view/7448

Malinowski, B. (1978). Crimen y costumbre en la sociedad salvaje [5ta. Ed.]. Barcelona: Ariel.

Mayer, E. (2004). Casa, chacra y dinero. Economías domésticas y ecología en los Andes. Lima: IEP.

Mizrahi, E. (2017). Estado y producción de subjetividad en El Bonaerense. En Callegaro, A., Di Leo Razuk, A. y Mizrahi, E. (Compiladores). Cine y cambio social: imágenes sociopoliticas de la Argentina 2002-2012. San Justo: Universidad nacional de La Matanza, 133-154. Recuperado de: http://biblioteca. clacso.edu.ar/clacso/se/20170630011806/Cine_y_cambio_ social.pdf

Ramírez, R. (2007). Institucionalización de niños y adolescentes. Promoción de la Infancia. Boletín de la Unidad de Post-Grado de la Facultad de Ciencias sociales Maestría en Politica Social con mención en Promoción de la Infancia. Año I N. 2. Lima: Facultad de Ciencias Sociales, UNMSM.

Trapero, P. (2008). Entrevistado por Hernán Schell. Revista El amante Cine, N. 192 mayo 2008, 6-7. Buenos Aires, Argentina. Recuperado de: http://www.elamante.com/ 